\title{
Chemical Management of Invasive Shot Hole Borer and Fusarium Dieback in California Sycamore (Platanus racemosa) in Southern California
}

Joey S. Mayorquin, Joseph D. Carrillo, Mathias Twizeyimana, Beth B. Peacock, Kameron Y. Sugino, Francis Na, and Danny H. Wang, Department of Microbiology and Plant Pathology, University of California, Riverside 92521; John N. Kabashima, University of California Cooperative Extension (Orange County), Irvine 92618; and Akif Eskalen, ${ }^{\dagger}$ Department of Plant Pathology, University of California, Davis

\begin{abstract}
Fusarium dieback (FD) is a new vascular disease of hardwood trees caused by Fusarium spp. and other associated fungal species which are vectored by two recently introduced and highly invasive species of ambrosia beetle (Euwallacea spp. nr. fornicatus). One of these ambrosia beetles is known as the polyphagous shot hole borer (PSHB) and the other as the Kuroshio shot hole borer (KSHB). Together with the fungi that they vector, this pest-disease complex is known as the shot hole borer-Fusarium dieback (SHB-FD) complex. Mitigation of this pest-disease complex currently relies on tree removal; however, this practice is expensive and impractical given the wide host range and rapid advancement of the beetles throughout hardwoods in southern California. This study reports on the assessment of various pesticides for use in the management of SHB-FD. In vitro screening of 13 fungicides revealed that pyraclostrobin, trifloxystrobin, and azoxystrobin generally have lower effective concentration that reduces $50 \%$ of mycelial growth $\left(\mathrm{EC}_{50}\right)$ values across all fungal symbionts of PSHB and

$\mathrm{KSHB}$; metconazole was found to have lower $\mathrm{EC}_{50}$ values for Fusarium spp. and Paracremonium pembeum. Triadimefon and fluxapyroxad were not capable of inhibiting any fungal symbiont at the concentrations tested. A 1-year field study showed that two insecticides, emamectin benzoate alone and in combination with propiconazole, and bifenthrin, could significantly reduce SHB attacks. Two injected fungicides (tebuconazole and a combination of carbendazim and debacarb) and one spray fungicide (metconazole) could also significantly reduce SHB attacks. Bioassays designed to assess fungicide retention 1 year postapplication revealed that six of the seven fungicides exhibited some level of inhibition in vitro and all thiabendazole-treated trees sampled exhibiting inhibition. This study has identified several pesticides which can be implemented as part of an integrated pest management strategy to reduce SHB infestation in low to moderately infested landscape California sycamore trees and potentially other landscape trees currently affected by SHB-FD.
\end{abstract}

Shot hole borer-Fusarium dieback (SHB-FD) is a rapidly spreading pest-disease complex in which several fungal species are vectored by ambrosia beetles (Euwallacea spp. nr. fornicatus) that attack numerous hardwood tree species throughout California. First identified in Los Angeles in 2012 (Eskalen et al. 2013), SHB-FD has since spread into the surrounding counties of Orange, Riverside, San Bernardino, San Diego, Ventura, and Santa Barbara. More recently, SHB have been collected from beetle traps in the coastal county of San Luis Obispo (A. Eskalen, K. Corella, CalFire SLO, unpublished data). The destructive nature of SHB-FD is a result of the combined effect of its two related vectors, polyphagous shot hole borer (PSHB) and Kuroshio shot hole borer (KSHB) (Euwallacea spp. nr. fornicatus, Coleoptera: Scolytinae), along with their ambrosial fungal symbionts Fusarium euwallaceae S. Freeman, Z. Mendel, T. Aoki \& O'Donnell (Freeman et al. 2013) in the case of PSHB and F. kuroshium F. Na, J. D. Carrillo \& A. Eskalen (Na et al. 2018) in the case of KSHB. Graphium spp. are also associated with both PSHB and KSHB and Paracremonium pembeum is known to occur with PSHB. As the beetle burrows into host trees to construct galleries, it simultaneously inoculates host tissue with its ambrosial symbionts, which invade the host vasculature, resulting in the disruption of water

Current address of M. Twizeyimana: AgBiome, Inc., 104 T. W. Alexander Drive, Building 1, Research Triangle Park, NC 27709.

${ }^{\dagger}$ Corresponding author: A. Eskalen; E-mail: aeskalen@ucdavis.edu

J. S. Mayorquin and J. D. Carrillo contributed equally to this work.

Funding: Orange County Parks, Natural Communities Coalition, San Diego Association of Governments, Walt Disney Imagineering Research \& Development, Inc., and the U.S. Department of Agriculture, National Institute of Food and Agriculture (CA-R-PPA-5061-H).

Accepted for publication 8 January 2018.

(c) 2018 The American Phytopathological Society and nutrient transport, leading to dieback and, eventually, tree death in susceptible hosts (Eskalen et al. 2013; Mendel et al. 2012).

First reported in California in 2003 from insect traps, PSHB was collected from several hosts in the Los Angeles area; however, no record of host disease symptoms was reported from this collection (Rabaglia et al. 2006). Beginning in 2012, several backyard avocado trees and ornamentals in the Los Angeles area exhibited symptoms of an unknown dieback disease associated with the presence of woodboring beetles. These beetles were later identified as the same beetles initially detected in 2003 and subsequently identified as PSHB (Eskalen et al. 2012, 2013); furthermore, these beetles were also determined to be identical to beetles found causing the same disease in Israeli avocado groves (Mendel et al. 2012). The beetle was initially restricted to the Los Angeles and Orange County areas but continued to spread throughout southern California. In 2013, trees were similarly being affected in San Diego County. Although initially believed to be an extension of the initial Los Angeles/Orange County infestation, it was later confirmed that the beetles in San Diego County, although morphologically indistinguishable from PSHB, were in fact a separate but closely related species, later named KSHB (Stouthamer et al. 2017). These findings confirmed the occurrence of two related but separate invasive ambrosia beetle introductions in California and are a cause of great concern over the existence of two highly destructive pathosystems.

FD is characterized by several traits: signs of beetle boring activity, which include small entry holes approximately $0.85 \mathrm{~mm}$ in diameter and the presence of frass, while symptoms include wet spots, gumming, frass or powdery exudate at entry holes, and dieback symptoms of affected trees. These signs and symptoms vary by host but a combination of the symptoms above may show in a host or no obvious symptoms may be seen initially (Eskalen et al. 2013). The host range of SHB has been increasing over time since its discovery; in 2012, 207 of 335 hosts examined had signs and symptoms consistent with FD. From these 207 hosts, which belong to 58 plant families, 11 were species native to California and 13 were agricultural commodities currently in production in California. Nineteen of these species were determined to be reproductive hosts, in which the beetle could 
complete its full life cycle. They include both native plant species and agricultural commodities (Eskalen et al. 2013). As of 2017, the number of vulnerable hosts has increased to 342 tree species encompassing 63 plant families, and the number of reproductive hosts has more than doubled to include 57 tree species, with new additions being added regularly (http://eskalenlab.ucr.edu/shotholeborerhosts.html). The economic and ecological burden of SHB-FD on urban trees planted throughout California, tree crop production, and trees in native forests will be substantial. In the absence of effective control measures for this pest-disease complex, it has been suggested that the economic costs related to SHB-FD damage would exceed $\$ 36$ billion (McPherson 2016) for the removal of dying trees.

The management of ambrosia beetles is particularly challenging because these beetles spend most of their life within their hosts, emerging only to colonize nearby hosts, which drastically limits the exposure of these beetles to contact insecticides. Furthermore, the xylomycetophagous ambrosia beetles do not consume the wood of host trees as bark beetles do (Batra 1966; Beaver 1989; FranckeGrosmann 1967), which could be problematic if using injectable insecticides because it is unclear how much contact exposure occurs between beetle and insecticide. Cooperband et al. (2016) observed that PSHB adults develop within 22 days at $24^{\circ} \mathrm{C}$ and produce an average of 32 viable female offspring, and it is thought that adult beetles and larvae are present throughout the year, suggesting that beetle reproduction takes place year-round (Eatough Jones and Paine 2015). The high and constant reproductive output of PSHB suggests that multiple spray applications of contact insecticides would likely need to be made throughout the year because no clear window of beetle emergence can be accurately predicted in a given area. Thus, the use of injectable systemic insecticides would be more appropriate for management of this vector to circumvent these issues. Several studies have shown the efficacy of various insecticides in the management of various bark and ambrosia beetles in avocado (Peña et al. 2011), oak (Svihra et al. 2004), and elm (Pajares and Lanier 1989). However, the association of these beetles with symbiotic and auxiliary fungi presents another challenge because the symbionts of both PSHB and KSHB are known to be pathogenic on their hosts (Lynch et al. 2016; Mendel et al. 2012; Na et al. 2018). This highlights the possibility for two levels of management: one to directly manage vector populations and a second level which aims to manage the fungal populations established by SHB once a host has been invaded.

The symbiosis between SHB and their associated fungi is essential to the survival and persistence of these ambrosia beetles because they feed exclusively on the symbiotic mutualists. In addition to $F$. euwallaceae, the primary symbiont of PSHB, which is known to be essential for the beetle to complete its full life cycle and is likely required for gallery establishment in new hosts (Freeman et al. 2013, 2016), PSHB is also associated with two other fungi: Graphium euwallaceae Twizeyim., S. C. Lynch \& Eskalen and P. pembeum S. C. Lynch \& Eskalen (Lynch et al. 2016). G. euwallaceae likely serves as the primary food source for immature beetle stages but may also play a prominent role during initial gallery formation. $P$. pembeum is not required as a source of food for any stage of beetle development nor is it currently considered a symbiont; however, it could play a role as a fungal antagonist toward contaminating fungi within beetle galleries (Freeman et al. 2016; Lynch et. al. 2016). Similarly, KSHB is known to associate with two symbiotic fungi-F. kuroshium and G. kuroshium F. Na, J. D. Carrillo \& A. Eskalen-both of which presumably serve the same function in KSHB as $F$. euwallaceae and G. euwallaceae serve in PSHB. This complicated but required association between beetle and fungi highlights an intrinsic vulnerability of this system, whereby suppression of fungal symbionts and associates could have severe impacts on beetle establishment and development. Exploiting this obligatory relationship between SHB and their associated fungi could be useful in the management of SHBFD because fungicides could be used to restrict the growth of fungal populations within tree hosts which, in turn, would affect the endurance of SHB.
No management strategies outside of cultural practices are in place for the management of SHB-FD. Currently, tree removal is recommended for heavily infested trees, followed by either chipping or solarization of infested material (Eatough Jones and Paine 2015) to reduce beetle populations in localized areas, in addition to eliminating physical hazards imposed by declining, heavily infested trees. Although these practices are useful in the absence of other management strategies and will continue to be used as part of an integrated pest management (IPM) program, the removal of infested trees is not only laborious and costly (estimated between $\$ 650$ and 1,000 per tree) but also is not practical for large-scale land management. More costeffective practices of managing this SHB-FD complex are clearly needed. The objectives of this study were to (i) identify fungicides which inhibit the growth of SHB symbionts in vitro, (ii) assess pesticide efficacy in planta in reducing PSHB attack levels over time, and (iii) recommend an immediate chemical management strategy for SHB-FD in California which could be used as part of an IPM program for SHB-FD on landscape trees in California.

\section{Materials and Methods}

Fungal isolates. Twelve isolates of $F$. euwallaceae, nine isolates of $F$. kuroshium, five isolates of both G. euwallaceae and G. kuroshium, and four isolates of $P$. pembeum were used in the in vitro fungicide screening experiment. These isolates were recovered from samples collected between 2012 and 2015 from avocado (Persea americana), box elder (Acer negundo), castor bean (Ricinus communis), California sycamore (Platanus racemosa), weeping acacia (Acacia floribunda), and coast live oak (Quercus agrifolia) showing symptoms of FD in Los Angeles, Orange, and San Diego Counties in California (Table 1). Fungal isolation from plant material was carried out by briefly flaming plant samples and removing the outer surface with a sterile paring knife to reveal internal vascular necrosis. Wood pieces were excised from the leading margin of necrotic tissue and placed onto potato dextrose agar amended with $0.01 \%$ tetracycline hydrochloride (PDA-t). Cultures were incubated at $25^{\circ} \mathrm{C}$ for 3 to 5 days and pure cultures were obtained by scraping emerging fungal colonies with a sterile inoculation loop, streak plating onto water agar, and incubating plates at $25^{\circ} \mathrm{C}$ for $24 \mathrm{~h}$. After $24 \mathrm{~h}$, single germinating conidia were transferred from water agar plates with the aid of a stereomicroscope to fresh PDA plates to establish pure cultures. To confirm fungal identity, morphological and molecular methods were followed as described by Freeman et al. (2013), Lynch et al. (2016), and $\mathrm{Na}$ et al. (2018).

In vitro fungicide screening. Eleven fungicides belonging to different chemical families (Table 2) were tested in vitro to determine the effective concentration that reduces $50 \%$ of mycelial growth $\left(\mathrm{EC}_{50}\right)$ values of the 35 isolates using the spiral gradient dilution method (Förster et al. 2004). Briefly, PDA $(50 \mathrm{ml})$ was poured into each $15-\mathrm{cm}$-diameter Petri dish at least $24 \mathrm{~h}$ before each fungicide suspension was applied. A $62.5-\mu l$ fungicide suspension from each of the stock suspensions was applied with a spiral plater (SGE; Spiral Biotech, Inc.) using the exponential deposition mode. The plates were incubated for approximately $3 \mathrm{~h}$ to allow the fungicides to diffuse into the agar medium and form a concentration gradient along the radius of the plate. Droplets $(10 \mu \mathrm{l})$ of conidial suspensions $\left(5 \times 10^{5} \mathrm{ml}\right)$ made from each fungal isolate were spread across the radial lines in predetermined plate positions using a sterile plastic pestle. There were control treatments consisting of PDA plates without fungicides added, to which the appropriate conidial suspension of each isolate was applied with a sterile plastic pestle. There were two replications per isolate and plates were incubated at $25^{\circ} \mathrm{C}$ for 3 to 5 days, depending on fungal species; and, at the end of this period, $\mathrm{EC}_{50}$ values were determined, as described by Förster et al. (2004).

Pesticide field trial. Field trials were established at three county regional parks located in Orange County California: Yorba Regional Park (33 $\left.{ }^{\circ} 52^{\prime} 14.4^{\prime \prime} \mathrm{N}, 117^{\circ} 45^{\prime} 45.2^{\prime \prime} \mathrm{W}\right)$, Carbon Canyon Regional Park ( $\left.33^{\circ} 55^{\prime} 19.9^{\prime \prime} \mathrm{N}, 117^{\circ} 50^{\prime} 13.2^{\prime \prime} \mathrm{W}\right)$, and Ted Craig Regional Park $\left(33^{\circ} 54^{\prime} 10.2^{\prime \prime} \mathrm{N}, 117^{\circ} 53^{\prime} 04.7^{\prime \prime} \mathrm{W}\right)$. Sites were chosen based on two criteria: availability of SHB hosts and level of infestation. The most common host trees available at all three sites included $P$. racemosa, 
Platanus $\times$ acerifolia, Alnus rhombifolia, Liquidambar styraciflua, Q. agrifolia, Salix laevigata, and Populus fremontii, with Platanus racemosa being the most abundant host tree available (Arbor Access Tree Inventory; West Coast Arborists). To evaluate the level of infestation, trees were classified by the number of beetle entry holes present on an approximately 1-m-length section on the bole beginning approximately $1 \mathrm{~m}$ from the soil line and dieback presence according to the following criteria: low infestation $(<30$ entry holes and no dieback), moderate infestation ( $\geq 30$ entry holes and no dieback), and heavy infestation ( $\geq 30$ entry holes and dieback present).

Table 1. Fungal isolates used in the in vitro fungicide screening experiment

\begin{tabular}{|c|c|c|c|c|c|}
\hline Species & Isolate & Host & Host scientific name & Location & County $^{z}$ \\
\hline Fusarium euwallaceae & UCR4082 & Avocado & Persea americana & La Habra & LA \\
\hline F. euwallaceae & UCR4109 & Avocado & P. americana & San Marino & LA \\
\hline F. euwallaceae & UCR4147 & Avocado & P. americana & San Marino & LA \\
\hline F. euwallaceae & UCR4152 & Avocado & P. americana & Hacienda Heights & LA \\
\hline F. euwallaceae & UCR4128 & Box elder & Acer negundo & Hacienda Heights & LA \\
\hline F. euwallaceae & UCR4175 & Box elder & A. negundo & San Marino & LA \\
\hline F. euwallaceae & UCR3200 & Box elder & A. negundo & San Marino & LA \\
\hline F. euwallaceae & UCR4336 & Box elder & A. negundo & San Marino & LA \\
\hline F. euwallaceae & UCR4060 & Castor bean & Ricinus communis & Orange Co. River & Orange \\
\hline F. euwallaceae & UCR4086 & Castor bean & R. communis & Azusa & LA \\
\hline F. euwallaceae & UCR4100 & Castor bean & R. communis & Orange Co. River & Orange \\
\hline F. euwallaceae & UCR4149 & Castor bean & R. communis & La Habra & LA \\
\hline F. kuroshium & UCR3645 & Avocado & P. americana & Fallbrook & $\mathrm{SD}$ \\
\hline F. kuroshium & UCR3654 & Avocado & P. americana & Bonsall & $\mathrm{SD}$ \\
\hline F. kuroshium & UCR3661 & Avocado & P. americana & Escondido & $\mathrm{SD}$ \\
\hline F. kuroshium & UCR3062 & Avocado & P. americana & Escondido & SD \\
\hline F. kuroshium & UCR3641 & California sycamore & Platanus racemosa & E1 Cajon & SD \\
\hline F. kuroshium & UCR3643 & California sycamore & P. racemosa & E1 Cajon & $\mathrm{SD}$ \\
\hline F. kuroshium & UCR3644 & California sycamore & P. racemosa & E1 Cajon & SD \\
\hline F. kuroshium & UCR3616 & California sycamore & P. racemosa & San Diego & $\mathrm{SD}$ \\
\hline F. kuroshium & UCR3615 & Castor bean & R. communis & San Diego & $\mathrm{SD}$ \\
\hline Graphium euwallaceae & UCR2974 & Castor bean & R. communis & San Marino & LA \\
\hline G. euwallaceae & UCR2975 & Box elder & A. negundo & San Marino & LA \\
\hline G. euwallaceae & UCR2977 & Weeping acacia & Acacia floribunda & San Marino & LA \\
\hline G. euwallaceae & UCR2979 & Coast live oak & Quercus agrifolia & San Marino & LA \\
\hline G. euwallaceae & UCR2980 & Avocado & P. americana & San Marino & LA \\
\hline G. kuroshium & UCR4593 & Avocado & P. americana & Fallbrook & $\mathrm{SD}$ \\
\hline G. kuroshium & UCR4606 & Avocado & P. americana & Bonsall & $\mathrm{SD}$ \\
\hline G. kuroshium & UCR4609 & Avocado & P. americana & Bonsall & $\mathrm{SD}$ \\
\hline G. kuroshium & UCR4616 & Avocado & P. americana & Escondido & $\mathrm{SD}$ \\
\hline G. kuroshium & UCR4618 & Avocado & P. americana & Escondido & $\mathrm{SD}$ \\
\hline Paracremonium pembeum & UCR2982 & Box elder & A. negundo & San Marino & LA \\
\hline P. pembeum & UCR2991 & California sycamore & $P$. racemosa & San Marino & LA \\
\hline P. pembeum & UCR2983 & Avocado & P. americana & San Marino & LA \\
\hline P. pembeum & UCR2994 & Castor bean & $R$. communis & San Marino & LA \\
\hline
\end{tabular}

${ }^{\mathrm{z}} \mathrm{LA}=$ Los Angeles County and SD $=$ San Diego County.

Table 2. Fungicides tested in the in vitro screening and field trial for their ability to manage Fusarium dieback

\begin{tabular}{llllcc}
\hline Active ingredient & Trade name & Chemical family & Manufacturer & Field rate applied $^{\mathbf{y}}$ & Application method $^{\mathbf{z}}$ \\
\hline Bacillus subtilis & Cease & Microbial & BioWorks & $1 \%$ (vol/vol) solution & Trunk spray \\
Bifenthrin & Onyx & Pyrethroid & FMC & $240 \mathrm{~g} /$ liter & Trunk spray \\
Carbendazim + debacarb & Fungisol & Benzimidazole & Mauget & $2.4 \mathrm{ml} / \mathrm{cm} \mathrm{DBH}$ & Injection \\
Emamectin benzoate & Tree-äge & Avermectin & ArborJet & $2.9 \mathrm{ml} / \mathrm{cm} \mathrm{DBH}$ & Injection \\
Metconazole & Tourney & Triazole & Valent USA & $18.1 \mathrm{~g} / \mathrm{cm} \mathrm{DBH}$ & Trunk spray \\
Propiconazole & Propizol & Triazole & ArborJet & $3.9 \mathrm{ml} / \mathrm{cm} \mathrm{DBH}$ & Injection \\
Tebuconazole & Tebuject 16 & Triazole & Mauget & $2.4 \mathrm{ml} / \mathrm{cm} \mathrm{DBH}$ & Injection \\
Thiabendazole & Arbotect 20-S & Benzimidazole & Syngenta & $2.4 \mathrm{ml} / \mathrm{cm} \mathrm{DBH}$ & Injection \\
Azoxystrobin & Abound & Strobilurin & Syngenta & $\ldots$ & $\ldots$ \\
Fluopyram & Luna Privelage & Benzamide-pyridine & Bayer & $\ldots$ & \\
Fluxapyroxad & Xemium & Carboxamide & BASF & $\ldots$ & $\ldots$ \\
Myclobutanil & Rally & Triazole & DowAgroSciences & $\ldots$ & $\ldots$ \\
Pyraclostrobin & Cabrio & Strobilurin & BASF & $\ldots$ & $\ldots$ \\
Pyrimethanil & Scala & Anilopyrimidine & Bayer & $\ldots$ & $\ldots$ \\
Triadimefon & Bayleton Flo & Triazole & Bayer & $\ldots$ & $\ldots$ \\
Trifloxystrobin & Flint & Strobilurin & Bayer & $\ldots$ & $\ldots$ \\
Triflumizole & Procure & Imidazole & Chemtura & $\ldots$ & \\
\hline
\end{tabular}

${ }^{y} \mathrm{DBH}=$ diameter at breast height; applications of B. subtilis, bifenthrin, and metconazole were mixed with 2\% (vol/vol) penetrant (Pentra-Bark; Quest Products Corp.).

${ }^{\mathrm{z}}$ Trunk sprays were applied with a trunk-mounted sprayer until run off. 
Trees from all three sites ranged from 18 to $71 \mathrm{~cm}$ in diameter at breast height $(\mathrm{DBH})$ and levels of infestation were as follows: Yorba Regional Park (low infestation), Ted Craig Regional Park (moderate infestation), and Carbon Canyon Regional Park (high infestation). Based on these criteria, 80 trees from each park were randomly selected for inclusion into the pesticide trial using a randomized complete block design, with each park functioning as a block. On 25 July 2015 , the DBH of each tree was recorded and the number of beetle entry holes counted from an approximately 1-m-length section on the bole beginning approximately $1 \mathrm{~m}$ from the soil line. Each of the 80 trees was randomly assigned to 1 of 10 pesticide treatments for a total of 8 trees per treatment. Assigned trees were sorted by DBH and initial entry holes to check for similar DBH and entry holes across all treatments using analysis of variance (ANOVA); no significant differences $(P>0.05)$ in initial entry holes were detected between treatments. On 11 to 12 August 2015, trees were treated with the pesticides and rates in Table 2. Trees treated with thiabendazole, emamectin benzoate, propiconazole, and emamectin benzoate + propiconazole were injected using the Arborjet QUIK-jet Air injector (Arborjet); trees treated with carbendazim + debacarb and tebuconazole were injected using Chemjet tree injectors (Queensland Plastics); and trees treated with Bacillus subtilis (strain QST713), metconazole, and bifenthrin were mixed with a bark penetrant (Pentra-Bark; Quest Products Corp.) at a rate of $2.9 \mathrm{ml} / \mathrm{cm} \mathrm{DBH}$ and applied with a spray rig until run-off. Trees were evaluated every month (approximately 28 days), for 12 months following pesticide application by counting the number of beetle entry holes on the bole, as described above. Loose bark from trees was removed with a plastic putty knife. Oil-based paint pens (Diagraph MSP) were used to count entry holes by dotting to the right of beetle entry holes and a unique color pen was used for every month.

Fungicide retention bioassay. Bioassays were conducted according to the method of Mayfield et al. (2008) to determine fungicide retention in field-injected trees. At 12 months postinjection, tree cores were taken from all treated trees at Yorba Regional Park for all treatments except bifenthrin and emamectin benzoate treatments, because these pesticides are insecticides. Briefly, wood cores (approximately 1 by $8 \mathrm{~cm}$ each) were removed from pesticide-treated and untreated trees using an increment borer in four cardinal directions at approximately $1.2 \mathrm{~m}$ above the soil line. Wood cores were surface disinfested with $95 \%$ ethanol and flamed to burn off excess ethanol. Bark was removed and remaining xylem cores were placed onto PDA-t seeded with spores $\left(1 \times 10^{6} \mathrm{ml}\right)$ of $F$. euwallaceae (UCR4082), which were applied using an atomizer. Plates were incubated for 6 days and scored (ratings 0 to 3 ) using a modified rating scale from Stennes and French (1987) as follows: $0=$ fungal growth over entire plug, $1=$ fungal growth on part of the plug, $2=$ no fungal growth on plug, and $3=$ no fungal growth on plug + presence of zone of inhibition (ZOI) in agar medium. Scores $\geq 1$ are considered to show inhibition. The number of trees showing inhibition was calculated from the presence of at least one core with a score $\geq 1$ and percent inhibition was calculated as the percentage of plugs per tree with scores $\geq 1$.

Statistical analyses. All statistical analyses were performed using $\mathrm{R}$ (version 3.2.3). $\mathrm{EC}_{50}$ values were transformed using logarithmic transformation $\left(\log _{10}\right)$ prior to analysis to normalize data, as suggested by Liang et al. (2015), and evaluated using the ShapiroWilk test of normality. Homoscedasticity for all independent, in vitro runs for each fungal species tested was evaluated using Levene's test; no heterogeneity was detected and, thus, data from individual runs were combined. $\mathrm{EC}_{50}$ values were tested by ANOVA under a linear regression model and mean $\mathrm{EC}_{50}$ values of all fungicides were compared using Tukey's honestly significant difference at $\alpha=0.05$. Count data from the fungicide applications in planta were transformed to attacks of SHB per square meter based on the total area of the individual trees that were counted for the duration of the experiment. The transformed data were not normally distributed and zero inflated when analyzed using the "lattice" package (Sarkar 2008) in $\mathrm{R}$; therefore, regression analysis was performed using a generalized linear model with a negative binomial link function and performed using the "MASS" package (Venables and Ripley 2002) in R. The model was blocked by location. Post hoc analysis was done by first constructing a contrast matrix in order to compare all treatments to the control then by using the "multcomp" package (Hothorn et al. 2008) in R, with link function glht for comparison of all fungicide treatments to the control based on the matrix. Bioassay inhibition data were tested using a generalized linear model with binomial distribution and logit link function after coding individual tree core inhibition scores as either 0 (inhibition rating 0 ) or 1 (inhibition rating $\geq 1$ ) for each treatment. Independent contrasts were performed between control treatment and each pesticide treatment, except for $B$. subtilis treatment, to determine significance at $\alpha=0.05$.

\section{Results}

In vitro fungicide screening. There were significant differences $(P<0.001)$ among 13 fungicides used in the in vitro fungicide screening experiment; however, no significant differences were recorded among the $12 F$. euwallaceae isolates $(P=0.791)$ (Table 3). Metconazole had the lowest $\mathrm{EC}_{50}$ value (0.031); however, its $\mathrm{EC}_{50}$ did not significantly differ $(P>0.05)$ to that of pyraclostrobin. Pyraclostrobin had significantly lower $\mathrm{EC}_{50}$ values than other strobilurins tested (azoxystrobin and trifloxystrobin). Pyrimethanil had the highest $\mathrm{EC}_{50}$ while two other fungicides (fluxapyroxad and trifloxystrobin) had $0 \%$ (or no) inhibition when tested against $12 \mathrm{~F}$. euwallaceae isolates. Like $F$. euwallaceae, there were significant differences $(P<0.001)$ among the 13 fungicides tested in vitro against $F$. kuroshium (Table 3 ); however, no significant differences were detected between the nine isolates of $F$. kuroshium $(P=0.299)$. Pyraclostrobin had the lowest $\mathrm{EC}_{50}$ value $(0.005)$ and differed significantly $(P<0.05)$ from the mean value for metconazole (0.0190). Fluopyram had the highest $\mathrm{EC}_{50}$ value while pyrimethanil, fluxapyroxad, and triadimefon showed no inhibition of Fusarium spp. at the concentrations tested. Pyrimethanil was observed to inhibit growth of $F$. euwallaceae but not $F$. kuroshium.

There were significant differences $(P<0.001)$ among 12 fungicides (G. euwallaceae) and 11 fungicides $(G$. kuroshium) used in the in vitro fungicide screening experiment; however, no significant differences were recorded within species for the five $G$. euwallaceae isolates $(P=0.862)$ or $G$. kuroshium isolates $(P=0.341)$ (Table 3$)$. Pyraclostrobin had the lowest $\mathrm{EC}_{50}$ values for both $G$. euwallaceae (0.007) and G. kuroshium (0.004); however, its $\mathrm{EC}_{50}$ did significantly differ $(P<0.05)$ from those of the other strobilurins tested (pyraclostrobin and azoxystrobin). Triflumizole had highest $\mathrm{EC}_{50}$ while three other fungicides (myclobutanil, fluxapyroxad, and triadimefon) had no inhibition when tested against 10 Graphium spp. isolates. Furthermore, no inhibition with fluopyram was observed when tested against $G$. euwallaceae.

There were significant differences $(P<0.001)$ among 13 fungicides used in the in vitro fungicide screening experiment against Paracremonium pembeum; however, no significant differences were recorded among the four $P$. pembeum isolates $(P=0.217)$ (Table 3$)$. Pyraclostrobin had the lowest $\mathrm{EC}_{50}(0.023)$; however, its $\mathrm{EC}_{50}$ did not significantly differ $(P>0.05)$ from trifloxystrobin. Thiabendazole had the highest $\mathrm{EC}_{50}$ while three other fungicides (pyrimethanil, fluxapyroxad, and triadimefon) had no inhibition when tested against four $P$. pembeum isolates.

Pesticide field trial. During this study, two trees (one treated with bifenthrin and one treated with metconazole) died and were removed in April 2016 at Yorba Regional Park and three trees (one each from treatments of emamectin benzoate, metconazole, and bifenthrin) were removed in February 2016 from Carbon Canyon Regional Park due to hazard concerns; data collected from these five trees prior to death or removal were excluded from data analysis. Analysis of mean attacks per square meter of untreated control trees plotted by month by site revealed overall increases in the number of attacks per square meter (Fig. 1). Yorba Regional Park (low infestation) attacks per square meter steadily increased throughout the 12-month study. Craig Regional Park (moderate infestation) attacks per square meter increased throughout the initial count period to the 3rd month (November), with a slower increase in attacks per square meter from the 4th month throughout the 9th month (May), and increases in attacks per square meter continued again from the 10th month to the 12th month (August). Carbon Canyon Regional Park (heavy 
infestation) attacks per square meter increased throughout the initial count period to the $3 \mathrm{rd}$ month (November), followed by a plateau of overall attacks per square meter from the 4th through the 10th month (June), and an increase in attacks per square meter observed during the 11th month (July). A reduction in attacks per square meter at Carbon Canyon Regional Park was observed during the 12th month (August) due to bark sloughing off, resulting in lower attacks per square meter recorded at this site. Analysis of attacks per square meter by quarter $(\mathrm{Q})$ for all sites $(\mathrm{Q} 1=$ September to November, $\mathrm{Q} 2=$ December to February, Q3 = March to May, and Q4 = June to August) revealed Q3 to have significantly more increases in attacks per square meter than all other quarters.

Significant differences in attacks were observed when comparing parks; therefore, each park was analyzed individually. Trees at Yorba Regional Park revealed no treatments to have significantly fewer attacks per square meter than untreated control trees (Fig. 2). Trees at Craig Regional Park treated with tebuconazole and bifenthrin had significantly fewer $(P<0.001)$ attacks per square meter than untreated controls (Fig. 2). Trees at Carbon Canyon Regional Park treated with tebuconazole and metconazole had significantly fewer $(P<0.001)$ attacks per square meter than untreated controls, followed by carbendazim + debacarb $(P<0.01)$, emamectin benzoate, and emamectin benzoate + propiconazole $(P<0.05)($ Fig. 2$)$. However, emamectin benzoate and emamectin benzoate + propiconazole did not differ significantly $(P=0.059)$ from each other.

Fungicide retention bioassay. All treatments except for $B$. subtilis-treated trees and untreated (control) trees exhibited some level of inhibition (Table 4). Of the eight trees treated for each pesticide, thiabendazole-treated trees had the highest levels of inhibition, with all eight trees showing some level of inhibition; followed by five trees for propiconazole, propiconazole + emamectin benzoate, carbendazim + debacarb, and tebuconazole; and one tree for metconazole. Mean percentages of tree cores showing some level of inhibition per tree ranged from 25 to $50 \%$,with the highest mean observed in trees treated with propiconazole $(50 \%)$, followed by thiabendazole $(47 \%)$; propiconazole + emamectin benzoate $(45 \%)$; and carbendazim + debacarb, tebuconazole, and metconazole, all with means of $25 \%$. Tree cores taken from thiabendazole-treated trees showed ZOI on agar plates (score of 3) with a mean percentage of samples per tree ranging from 25 to $50 \%$; however, no tree cores taken from other pesticide-treated trees produced ZOI on agar plates. A significant difference $(P<0.001)$ was observed among the eight treatments tested. Independent contrast between untreated and pesticide-treated trees showed a significant difference in inhibition for thiabendazole $(P<0.001)$, propiconazole $(P=0.001)$, propiconazole + emamectin benzoate $(P=0.0004)$, carbendazim + debacarb $(P=0.0127)$, and tebuconazole $(P=0.0127)$. Inhibition

Table 3. Mean and standard deviation of effective concentration that reduces $50 \%$ of mycelial growth $\left(\mathrm{EC}_{50}\right)$ values for fungal associates of shot hole borers in in vitro fungicide experiment ${ }^{\mathrm{y}}$

\begin{tabular}{|c|c|c|c|c|c|c|c|c|c|c|}
\hline \multirow[b]{2}{*}{ Active ingredient } & \multicolumn{2}{|c|}{ Fusarium euwallaceae } & \multicolumn{2}{|c|}{ F. kuroshium } & \multicolumn{2}{|c|}{ Graphium euwallaceae } & \multicolumn{2}{|c|}{ G. kuroshium } & \multicolumn{2}{|c|}{$\begin{array}{l}\text { Paracremonium } \\
\text { pembeum }\end{array}$} \\
\hline & Conc & $\mathrm{EC}_{50}(\mu \mathrm{g} / \mathrm{ml})$ & Conc & $\mathrm{EC}_{50}(\mu \mathrm{g} / \mathrm{ml})$ & Conc & $\overline{E C_{50}(\mu \mathrm{g} / \mathrm{ml})}$ & Conc & $\left.\mathrm{EC}_{50} \mu \mathrm{g} / \mathrm{ml}\right)$ & Conc & $\mathrm{EC}_{50}(\mu \mathrm{g} / \mathrm{ml})$ \\
\hline Metconazole & 25 & $0.031 \pm 0.019 a$ & 100 & $0.019 \pm 0.007 b$ & 1,000 & $1.392 \pm 1.089 \mathrm{~d}$ & 1,000 & $0.943 \pm 0.136 \mathrm{e}$ & 100 & $0.102 \pm 0.054 b$ \\
\hline Pyraclostrobin & 100 & $0.037 \pm 0.019 \mathrm{a}$ & 100 & $0.005 \pm 0.002 \mathrm{a}$ & $(10)$ & $0.007 \pm 0.006 \mathrm{a}$ & 10 & $0.004 \pm 0.001 \mathrm{a}$ & 100 & $0.023 \pm 0.009 a$ \\
\hline Tebuconazole & 100 & $0.055 \pm 0.025 b$ & 100 & $0.240 \pm 0.103 \mathrm{~d}$ & 5,000 & $4.859 \pm 1.515 \mathrm{e}$ & 5,000 & $4.424 \pm 1.386 \mathrm{f}$ & 500 & $1.031 \pm 0.567 \mathrm{c}$ \\
\hline Trifloxystrobin & 100 & $0.058 \pm 0.023 b$ & 100 & $0.072 \pm 0.031 \mathrm{c}$ & 100 & $0.081 \pm 0.065 b$ & 100 & $0.042 \pm 0.016 b$ & 100 & $0.030 \pm 0.013 \mathrm{a}$ \\
\hline Thiabendazole & 500 & $0.189 \pm 0.039 \mathrm{c}$ & 1,000 & $1.400 \pm 0.195 \mathrm{f}$ & 1,000 & $4.444 \pm 0.695 \mathrm{e}$ & 1,000 & $0.616 \pm 0.143 \mathrm{~d}$ & 5,000 & $14.178 \pm 1.813 \mathrm{f}$ \\
\hline Azoxystrobin & 1,000 & $0.697 \pm 0.420 \mathrm{e}$ & 1,000 & $1.171 \pm 0.489 \mathrm{f}$ & 100 & $0.113 \pm 0.056 b$ & 100 & $0.047 \pm 0.022 b$ & 500 & $0.967 \pm 0.615 \mathrm{c}$ \\
\hline Fluopyram & 1,000 & $1.779 \pm 0.595 \mathrm{f}$ & 5,000 & $2.814 \pm 1.092 \mathrm{~g}$ & 5,000 & NI & NT & & 500 & $0.812 \pm 0.217 \mathrm{c}$ \\
\hline Myclobutanil & 1,000 & $2.171 \pm 1.695 \mathrm{f}$ & 1,000 & $1.291 \pm 0.341 \mathrm{f}$ & 5,000 & NI & 5,000 & NI & 5,000 & $4.467 \pm 1.400 \mathrm{e}$ \\
\hline Propiconazole & 1,000 & $0.423 \pm 0.262 \mathrm{~d}$ & 1,000 & $0.483 \pm 0.206 \mathrm{e}$ & 1,000 & $0.234 \pm 0.084 \mathrm{c}$ & 1,000 & $0.242 \pm 0.035 \mathrm{c}$ & 5,000 & $4.573 \pm 2.507 \mathrm{e}$ \\
\hline Triflumizole & 1,000 & $0.647 \pm 0.574 \mathrm{de}$ & 1,000 & $0.381 \pm 0.060 \mathrm{e}$ & 5,000 & $4.891 \pm 3.848 \mathrm{e}$ & 5,000 & $5.157 \pm 1.703 \mathrm{f}$ & 1,000 & $1.857 \pm 0.801 \mathrm{~d}$ \\
\hline Fluxapyroxad & 5,000 & NI & 5,000 & NI & 5,000 & NI & 5,000 & NI & 5,000 & NI \\
\hline Pyrimethanil & 5,000 & $4.768 \pm 2.959 \mathrm{~g}$ & 5,000 & NI & NT & $\ldots$ & NT & $\ldots$ & 5,000 & NI \\
\hline Triadimefon & 5,000 & NI & 5,000 & NI & 5,000 & NI & 5,000 & NI & 5,000 & NI \\
\hline $\operatorname{HSD}(\alpha=0.05)^{\mathrm{z}}$ & 0.052 & $\ldots$ & 0.029 & $\ldots$ & 0.064 & $\ldots$ & 0.014 & $\cdots$ & 0.041 & $\ldots$ \\
\hline
\end{tabular}

${ }^{y}$ Conc $=$ concentrations applied $(\mu \mathrm{g} / \mathrm{ml})$. Numbers are mean and standard deviation of $\mathrm{EC}_{50}$ values. Levels connected by the same letter are not significantly different. NI $=$ no inhibition and $\mathrm{NT}=$ not tested.

z Tukey's honestly significant difference.

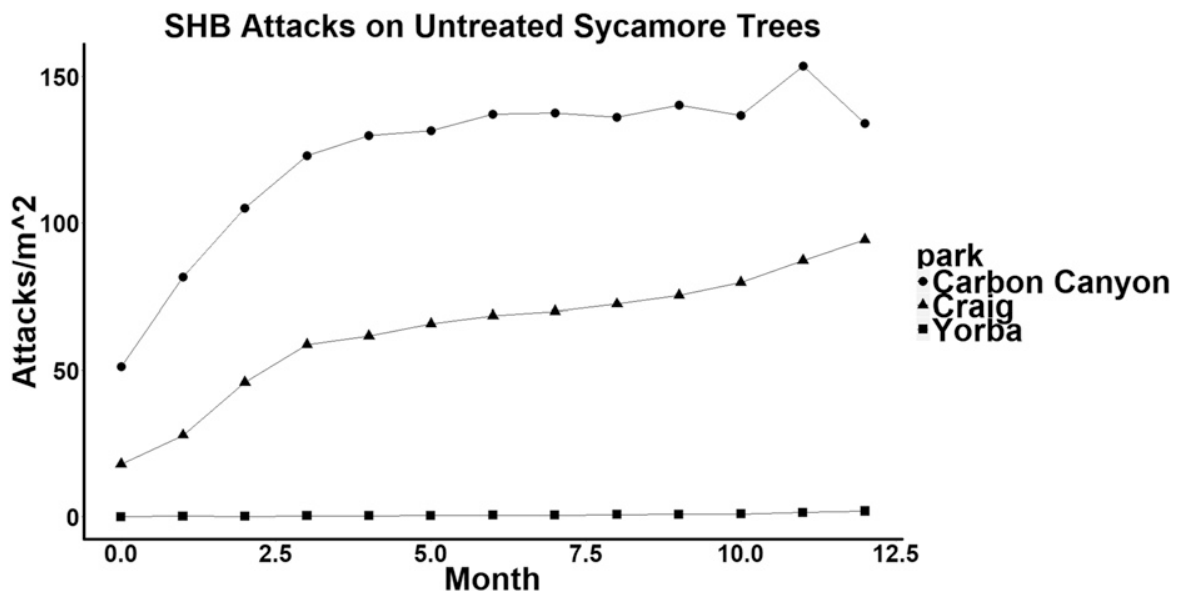

Fig. 1. Mean shot hole borer (SHB) attacks per square meter of untreated control trees over 12 months at three sites with various infestation rates (Yorba: low; Craig: moderate; and Carbon Canyon: heavy). 
observed in metconazole-treated trees was not significantly different $(P>0.05)$ from untreated control trees, nor was inhibition significantly different $(P>0.05)$ between trees treated with propiconazole and propiconazole + emamectin benzoate.

\section{Discussion}

SHB-FD is a destructive pest-disease complex causing significant damage to hardwood trees in southern California and, until recently,

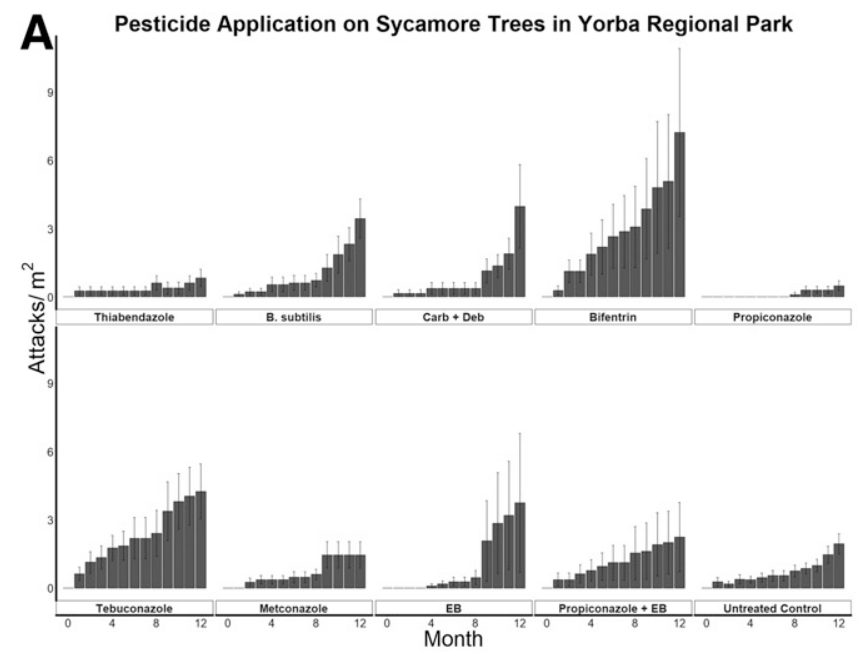

B Pesticide Application on Sycamore Trees in Craig Regional Park
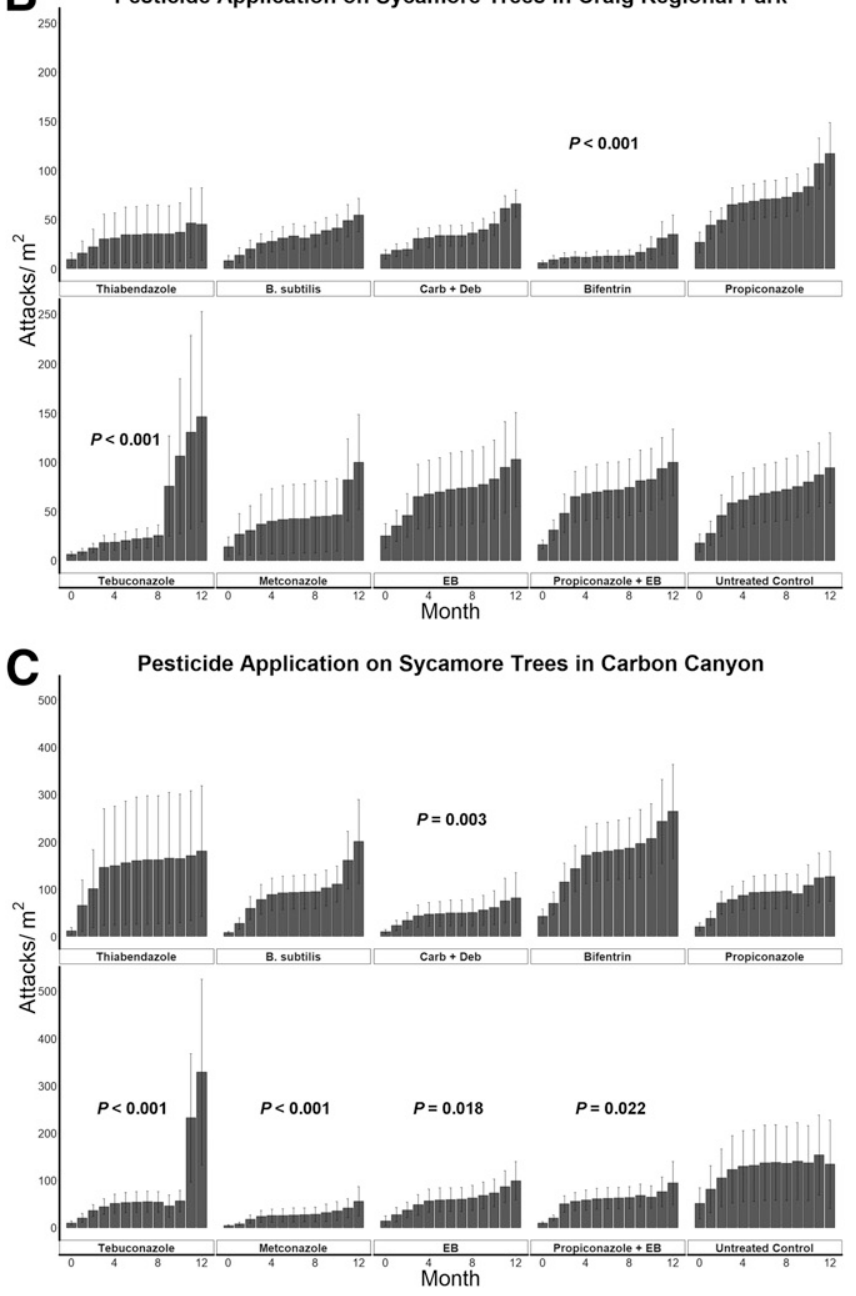

Fig. 2. Mean accumulated shot hole borer attacks per square meter for pesticide treated trees at A, Yorba Regional Park; B, Craig Regional Park; and C, Carbon Canyon Regional Park. Vertical bars represent standard error of means. $P$ values are derived from comparisons between individual treatments and untreated controls at $\alpha=0.05$. no management strategies outside of cultural practices (tree removal) existed. This study provides evidence for the efficacy of several pesticides, including fungicides, insecticides, and a combination thereof, in reducing SHB attacks in California sycamore. Overall, three triazole fungicides - tebuconazole, metconazole, and propiconazole (in combination with an insecticide) - were found to significantly reduce the number of beetle attacks on treated California sycamore trees in addition to trees treated with a mixture of carbendazim and debacarb in combination and one insecticide (emamectin benzoate). Although only one field application was done for each of the pesticides tested, bioassays of fungicide-treated trees 12 months postapplication revealed six of the seven treatments to exhibit some level of inhibition (retention) in vitro.

The management of wood-boring ambrosia beetles is difficult in the traditional context of insect chemical management because the use of contact insecticides can be negated by the lifestyle of these beetles, given that they spend most of their life within their host tree and relatively little time outside of the host, limiting the chance of exposure to sprayed insecticides; and also because they are not phloeophagous such as bark beetles (Beaver 1989). Due to the "cryptic" nature of these beetles, management strategies are primarily focused on an integrated approach, which can include the use of injectable, systemic pesticides in addition to sanitation and silviculture techniques that include removing infested branches and immediate treatment of infested material through either burning, burying, or chipping to reduce beetle populations in the area (USDA-APHIS 2011). However, the rapid expansion of the beetle population and wide host range of these beetles throughout southern California limits the reliability of sanitation and silviculture techniques alone in managing this pest-disease complex and, therefore, necessitates the need for chemical control strategies in landscape systems. This, combined with the fact that ambrosia beetles are dependent on their symbiotic fungi for survival, suggests that the use of fungicides may be better suited to the control of ambrosia beetles because any reduction in fungal vigor may potentially negatively affect the survival of ambrosia beetles.

In this study, both insecticides tested (emamectin benzoate and bifenthrin) were found to significantly reduce beetle attacks in infested trees; however, bifenthrin-treated trees had significantly reduced beetle attacks in moderately infested trees but not in heavily infested trees. Similarly, emamectin benzoate, when applied alone or in combination with propiconazole, had reduced beetle attacks in heavily infested trees and not in moderately infested trees. The reduction of attacks with emamectin benzoate treatment alone are contrary to the findings of Fettig et al. (2013), whereby emamectin benzoate applications alone were not sufficient in reducing tree mortality due to Dendroctonus ponderosae attacks on Pinus contorta if applications were made less than a year before protection was needed; however, injections of emamectin benzoate in combination with propiconazole were found to significantly reduce $D$. ponderosae attacks when injected the same year but before beetle flight. Of several injected systemic insecticides, only injection with emamectin benzoate into avocado provided partial control of redbay ambrosia beetle (Xyleborus glabratus) attacks (Ploetz et al. 2017). The findings of this study suggest that emamectin benzoate alone may be sufficient in reducing attacks from $\mathrm{SHB}$ because combination treatments with propiconazole did not result in significantly lower SHB attacks when compared together. Bifenthrin is a pyrethroid insecticide which is both a contact and stomach poison but is nonsystemic. The use of pyrenthroids as a management option for the control of bark and ambrosia beetles has been studied in several systems and found to be successful in the management of bark and ambrosia beetles in oak (Svihra et al. 2004), elm (Pajares and Lanier 1989), and apple (Ciglar and Baric 2000); however, not all pyrenthroids have been found to be consistently effective, especially for bifenthrin. Mizell and Riddle (2004) reported that bifenthrin-treated bolts consistently reduced the number of Asian ambrosia beetle attacks compared with untreated control bolts. Bifenthrin was also found to suppress D. brevicomis and Ips confuses in conifers but multiyear applications were suggested, depending on the pest system (Fettig et al. 2006). Peña 
et al. (2011), studying the chemical control of X. glabratus, found that avocado trees treated with bifenthrin and $\zeta$-cypermethrin had more $X$. glabratus attacks than any other treated tree and Carrillo et al. (2013) found bifenthrin to only be effective in suppressing $X$. glabratus for 4 days postapplication under field conditions. Eatough Jones et al. (2017) found that bifenthrin did not significantly reduce the number of PSHB attacks in California sycamore despite previous studies suggesting that bifenthrin-treated cut logs were more effective in preventing PSHB attacks than several of the other insecticides tested (Eatough Jones and Paine 2018). Additionally, emamectin benzoate-treated trees were found to have reduced numbers of PSHB attacks during the second month following insecticide application; however, this was the only time point after application that showed a reduction in PSHB attacks for emamectin benzoate treatment (Eatough Jones et al. 2017).

In this study, treatment of California sycamore with carbendazim in combination with debacarb was found to significantly reduce SHB attacks in heavily infested trees. Carbendazim is a benzimidazole and breakdown product of benomyl and has been extensively studied as an injectable in the treatment of Dutch elm disease (Gregory and Jones 1973) and other diseases such as oak wilt (Jones et al. 1973). The use of carbendazim in these studies indicated that injection as a prophylactic was more efficacious in reducing or even preventing symptom development than when used as a therapeutic treatment. Although a systemic fungicide, carbendazim has not been observed to move into new wood growth, thus necessitating the need for annual treatments (Nishijima and Smalley 1978; Stennes and French 1987). Debacarb, like carbendazim, is a benzimidazole which has been studied in the management of various diseases, including Diplodia tip blight of pine (Hartman et al. 2009) and in combination with carbendazim for Dutch elm disease (Lanier 1987). Hartman et al. (2009) reported that debacarb treatment led to the slowest increase in disease incidence but was not effective in preventing tip blight. Similarly, Lanier (1987) observed that debacarb did not prevent infection and was also not effective as a therapeutic; however, prophylactic injections appeared to effect symptom progression. Results from the bioassay in this study suggest that the combination product of carbendazim and debacarb is retained after 1 year of treatment because inhibition was observed in vitro in five of the eight trees sampled; however, it is not possible to determine which compound or whether both compounds were still present at high-enough concentrations in the wood to inhibit fungal growth, nor is it known whether carbendazim or debacarb is responsible for the fungal inhibition observed because neither product was tested singly in vitro on fungal growth.

Both metconazole and tebuconazole were found to significantly reduce SHB attacks in treated sycamores in this study and metconazole was found to have lower $\mathrm{EC}_{50}$ values across all fungi tested in vitro. Tebuconazole has been evaluated for the management of $D$. ponderosae on pine and was found to reduce tree mortality and blue stain of pine treated with a combination of tebuconazole and abamectin to a degree less than that of abamectin-treated trees alone
(Fettig et al. 2013). To our knowledge, metconazole has not been used in the management of bark or ambrosia beetles until recently. Eatough Jones et al. (2017) did not find metconazole treatment alone to be effective in reducing PSHB attacks in California sycamore, although reductions were observed in combination treatments of metconazole, bifenthrin, and emamectin benzoate when compared with untreated control trees. However, the lack of efficacy of single metconazole applications may be due to the short duration of the study (6 months) and adequate time had not passed for the effects of this compound to be seen. Although metconazole is known to be xylem mobile, this treatment was not injected during this study but was applied as a spray mixed with a bark penetrant. No treatment of metconazole without penetrant was applied in this study; however, it is possible that the bark penetrant facilitates the movement of metconazole into the host vasculature for a period of time. Results from the bioassay showed little retention (one of seven trees) of metconazole after 12 months postapplication, suggesting that spray treatments of metconazole, although efficacious in a season, likely need to be applied yearly. The triazole propiconazole by itself was not found to significantly reduce beetle attacks but was found to reduce beetle attacks when combined with the insecticide emamectin benzoate. This contrasts with the in vitro fungicide results, where propiconazole was found to inhibit fungal growth of all symbionts tested. Propiconazole has been studied for the treatment of laurel wilt disease in Florida and was found to be effective in vitro at a concentration of $0.1 \mathrm{ppm}$ in completely inhibiting Raffaelea lauricola, and trees treated with injections of propiconazole did not develop crown wilt symptoms for at least 30 weeks postinjection (Mayfield et al. 2008). Ploetz et al. (2011) reported similar results with several triazoles in vitro and in planta against $R$. lauricola and determined that several triazoles, including propiconazole, had the most activity against $R$. lauricola. It is unclear why single propiconazole treatments were not effective during this study, given that propiconazole is systemic and showed activity in both in vitro screens and in trees receiving combination treatments of propiconazole and emamectin benzoate.

Thiabendazole has been studied for the management of Dutch elm disease (Stennes and French 1987) and laurel wilt (Mayfield et al. 2008; Ploetz et al. 2011). Preventative treatments with thiabendazole prior to inoculation with Ophiostoma novo-ulmi provided protection to trees for two seasons and thiabendazole was found to persist in new wood growth for three growing seasons (Stennes 1981; Stennes and French 1987). Thiabendazole was found to inhibit $R$. lauricola growth in vitro at $10 \mathrm{ppm}$ (Mayfield et al. 2008) and greenhouse studies indicated that thiabendazole could reduce symptom severity in $R$. lauricola-inoculated plants, although to a lesser extent than that of propiconazole-treated plants. The results from this study indicate that thiabendazole was not effective in reducing attacks of SHB on California sycamore even though thiabendazole was effective in vitro against the various fungi and that all thiabendazole-treated trees sampled exhibited inhibition in bioassays. It has been suggested that products with longer retention times but reduced fungitoxicity may

Table 4. Fungicide retention bioassay from treated California sycamore trees

\begin{tabular}{|c|c|c|c|c|c|c|c|}
\hline \multirow[b]{2}{*}{ Treatment } & \multicolumn{2}{|r|}{ Number of } & \multicolumn{3}{|c|}{$\begin{array}{c}\text { Samples per tree exhibiting } \\
\text { inhibition }(\%)\end{array}$} & \multicolumn{2}{|c|}{$\begin{array}{l}\text { Samples per tree } \\
\text { exhibiting ZOI in } \\
\text { agar }(\%)^{\mathrm{x}}\end{array}$} \\
\hline & Trees & Trees with inhibition ${ }^{y}$ & Mean & Range & $P$ value $^{\mathrm{z}}$ & Mean & Range \\
\hline Thiabendazole & 8 & 8 & 47 & $25-75$ & $<0.001$ & 16 & $25-50$ \\
\hline Propiconazole & 8 & 5 & 50 & $25-100$ & 0.001 & 0 & 0 \\
\hline Propiconazole + emamectin benzoate & 8 & 5 & 45 & $25-75$ & 0.004 & 0 & 0 \\
\hline Carbendazim + debacarb & 8 & 5 & 25 & 25 & 0.0127 & 0 & 0 \\
\hline Tebuconazole & 8 & 5 & 25 & 25 & 0.0127 & 0 & 0 \\
\hline Metconazole & 7 & 1 & 25 & 25 & $>0.05$ & 0 & 0 \\
\hline Bacillus subtilis & 8 & 0 & $\ldots$ & $\ldots$ & $\ldots$ & $\ldots$ & $\ldots$ \\
\hline Untreated & 8 & 0 & $\ldots$ & $\ldots$ & $\ldots$ & $\ldots$ & $\ldots$ \\
\hline
\end{tabular}

${ }^{\mathrm{x}} \mathrm{ZOI}=$ zone of inhibition.

${ }^{\mathrm{y}}$ Trees with samples exhibiting inhibition.

${ }^{\mathrm{z}} P$ values for treatments are in comparison with untreated controls using independent contrast. 
be more important for the management of these diseases (Ploetz et al. 2011; Stennes 2000). Although not effective in significantly reducing beetle attacks, the use of thiabendazole due to its retention should be further investigated for FD, especially in nonreproductive hosts where beetle colonization is not a concern but the potential for fungal deposition is.

The use of insecticides or fungicides is promising for the management of SHB-FD in southern California, especially when used as part of an IPM strategy for this pest-disease complex. Despite the efficacy of several pesticides shown in this study, several considerations must be given to the recommendations and conclusions to be drawn from the results of this trial. Further chemical studies using other hosts of SHB-FD and including longer trial times ( $>1$ year) will be necessary to determine the efficacy of these pesticides for use in particular hosts as well as to determine the length of time for which a product can provide adequate protection. Fungicide retention bioassays in avocado treated with several compounds used in this study show no inhibition against fungal symbionts tested, despite these trials being active for 1 year (J. D. Carrillo and A. Eskalen, unpublished). This lack of inhibition may suggest a difference in host vascular structure which is affecting the uptake and distribution of various pesticides. Other factors such as tree health, soil moisture, and temperature can all affect the uptake and distribution of a product (Fettig et al. 2013, 2014). Additionally, the degree of SHB-FD infection of a host is likely to affect the uptake and distribution of a product because heavily infested trees have more vasculature compromised by both beetle boring and fungal colonization, thereby reducing the efficacy of a product. As noted by Eatough Jones et al. (2017), the limited pesticide efficacy from their study may be due to both the advanced level of infestation of the trees in addition to the length of time (6 months) for which the trees were monitored. Future long-term studies involving multiple SHB-FD hosts will be necessary to further evaluate product efficacy as well as determine specific management protocols for individual hosts.

\section{Suggested Management}

Based on the result of this study, the following recommendations are given for the chemical management of SHB-FD on landscape sycamore trees: (i) careful monitoring of trees of interest, including surrounding trees, is recommended at all times; (ii) pesticides should only be applied to trees with low to moderate levels of infestation; applications should not be made on noninfested trees because no preventative treatments have been reported, nor is it likely that applications to heavily infested trees will "rescue" these trees from SHB-FD; (iii) after pesticide application, trees should be monitored regularly and any routine maintenance (i.e., pruning) should be performed as necessary; and (iv) heavily infested trees serve as "amplifier trees" of SHB and contribute to local beetle populations and may also pose a physical hazard and, therefore, should be removed and infested wood sanitized appropriately. For up-to-date information regarding the management of SHB-FD, please visit http://eskalenlab.ucr.edu/pshb.html.

\section{Acknowledgments}

We wish to thank M. J. Dimson, M. Eatough Jones, C. Hanlon, and K. Moreno for field assistance; the staff of Orange County Parks for their cooperation during the field study; D. M. Grosman of Arborjet Inc. and A. E. Hope of J. J. Mauget Co. for technical assistance with fungicide applications; and the anonymous reviewers for their constructive comments. We would like to thank Orange County Parks, Natural Communities Coalition, San Diego Association of Governments, Walt Disney Imagineering Research \& Development, Inc., and National Institute of Food and Agriculture, U.S. Department of Agriculture (CA-R-PPA-5061-H) for their support.

\section{Literature Cited}

Batra, L. R. 1966. Ambrosia fungi: Extent of specificity to ambrosia beetles. Science 153:193-195.

Beaver, R. A. 1989. Insect-fungus relationships in the bark and ambrosia beetles. Pages 121-143 in: Insect-Fungus Interactions. 14th Symp. R. Entomol. Soc., Vol. 14. Academic Press, in Collaboration with the British Mycological Society.

Carrillo, D., Crane, J. H., and Peña, J. E. 2013. Potential of contact insecticides to control Xyleborus glabratus (Coleoptera: Curculionidae), a vector of laurel wilt disease in avocados. J. Econ. Entomol. 106:2286-2295.
Ciglar, I., and Baric, B. 2000. Bark beetle (Scolytidae) in Croatian orchards. Pages 299-308 in: Int. Conf. Integr. Fruit Prod.

Cooperband, M. F., Stouthamer, R., Carrillo, D., Eskalen, A., Thibault, T., Cossé, A. A., Castrillo, L. A., Vandenberg, J. D., and Rugman-Jones, P. F. 2016. Biology of two members of the Euwallacea fornicatus species complex (Coleoptera: Curculionidae: Scolytinae), recently invasive in the U.S.A., reared on an ambrosia beetle artificial diet. Agric. For. Entomol. 18:223-237.

Eatough Jones, M., Kabashima, J., Eskalen, A., Dimson, M., Mayorquin, J. S. Carrillo, J. D., Hanlon, C. C., and Paine, T. D. 2017. Evaluations of insecticides and fungicides for reducing attack rates of a new invasive ambrosia beetle (Euwallacea sp., Coleoptera: Curculionidae: Scolytinae) in infested landscape trees in California. J. Econ. Entomol. 110:1611-1618.

Eatough Jones, M., and Paine, T. D. 2015. Effect of chipping and solarization on emergence and boring activity of a recently introduced ambrosia beetle (Euwallacea sp., Coleoptera: Curculionidae: Scolytinae) in Southern California. J. Econ. Entomol. 108:1852-1859.

Eatough Jones, M., and Paine, T. Dw. 2018. Potential pesticides for control of a recently introduced ambrosia beetle (Euwallacea sp.) in southern California. J. Pest Sci. 91:237-246.

Eskalen, A., Gonzalez, A., Wang, D. H., Twizeyimana, M., Mayorquin, J. S., and Lynch, S. C. 2012. First report of a Fusarium sp. and its vector tea shot hole borer (Euwallacea fornicatus) causing Fusarium dieback on avocado in California. Plant Dis. 96:1070.

Eskalen, A., Stouthamer, R., Lynch, S. C., Rugman-Jones, P. F., Twizeyimana, M., Gonzalez, A., and Thibault, T. 2013. Host range of Fusarium dieback and its ambrosia beetle (Coleoptera: Scolytinae) vector in Southern California. Plant Dis. 97:938-951.

Fettig, C. J., Allen, K. K., Borys, R. R., Christopherson, J., Dabney, C. P., Eager, T. J., Gibson, K. E., Hebertson, E. G., Long, D. F., Munson, A. S., Shea, P. J., Smith, S. L., and Haverty, M. I. 2006. Effectiveness of bifenthrin (Onyx) and carbaryl (Sevin SL) for protecting individual, high-value conifers from bark beetle attack (Coleoptera: Curculionidae: Scolytinae) in the Western United States. J. Econ. Entomol. 99:1691-1698.

Fettig, C. J., Grosman, D. M., and Munson, A. S. 2013. Efficacy of abamectin and tebuconazole injections to protect of lodgepole pine from mortality attributed to mountain pine beetle (Coleoptera: Curculionidae) attack and progression of blue stain fungi. J. Entomol. Sci. 48:270-278.

Fettig, C. J., Munson, A. S., Grosman, D. M., and Bush, P. B. 2014. Evaluations of emamectin benzoate and propiconazole for protecting individual Pinus contorta from mortality attributed to colonization by Dendroctonus ponderosae and associated fungi. Pest Manage. Sci. 70:771-778.

Förster, H., Kanetis, L., and Adaskaveg, J. E. 2004. Spiral gradient dilution, a rapid method for determining growth responses and 50\% effective concentration values in fungus-fungicide interactions. Phytopathology 94:163-170.

Francke-Grosmann, H. 1967. Ectosymbiosis in wood-inhabiting insects. Pages 141-205 in: Symbiosis: Associations of Invertebrates, Birds, Ruminants, and Other Biota. Academic Press, Waltham, MA.

Freeman, S., Sharon, M., Dori-Bachash, M., Maymon, M., Belausov, E., Maoz, Y., Margalit, O., Protasov, A., and Mendel, Z. 2016. Symbiotic association of three fungal species throughout the life cycle of the ambrosia beetle Euwallacea nr. fornicatus. Symbiosis 68:115-128.

Freeman, S., Sharon, M., Maymon, M., Mendel, Z., Protasov, A., Aoki, T., Eskalen, A., and O'Donnell, K. 2013. Fusarium euwallaceae sp. nov., a symbiotic fungus of Euwallacea sp., an invasive ambrosia beetle in Israel and California. Mycologia 105:1595-1606.

Gregory, G. F., and Jones, T. W. 1973. Pressure injection of methyl 2-benzimidazole carbamate hydrochloride solution as a control for Dutch elm disease. U. D. Dep. Agric. For. Serv. Northeast. For. Exp. Stn., Upper Darby, PA.

Hartman, J. R., Vaillancourt, L. J., Flowers, J. L., and Bateman, A. M. 2009 Managing Diplodia tip blight of landscape Austrian pines. J. Arboric. 35:27-32.

Hothorn, T., Bretz, F., and Westfall, P. 2008. Simultaneous inference in general parametric models. Biometrical J. 50:346-363.

Jones, T. W., Gregory, G. F., and McWain, P. 1973. Pressure injection of solubilized benomyl for prevention and cure of oak wilt. Research Note NE171. U. D. Dep. Agric. For. Serv. Northeast. For. Exp. Stn., Upper Darby, PA.

Lanier, G. N. 1987. Fungicides for Dutch elm disease: Comparative evaluation of commercial products. J. Arboric. 13:189-195.

Liang, H.-J., Li, J.-L., Di, Y.-L., Zhang, A.-S., and Zhu, F.-X. 2015. Logarithmic transformation is essential for statistical analysis of fungicide EC50 values. J. Phytopathol. 163:456-464.

Lynch, S. C., Twizeyimana, M., Mayorquin, J. S., Wang, D. H., Na, F., Kayim, M., Kasson, M. T., Thu, P. Q., Bateman, C., Rugman-Jones, P., and Hulcr, J. 2016. Identification, pathogenicity and abundance of Paracremonium pembeum sp. nov. and Graphium euwallaceae sp. nov. two newly discovered mycangial associates of the polyphagous shot hole borer (Euwallacea sp.) in California Mycologia 108:313-329.

Mayfield, A. E., III, Barnard, E. L., Smith, J. A., Bernick, S. C., Eickwort, J. M., and Dreaden, T. J. 2008. Effect of propiconazole on laurel wilt disease development in redbay trees and on the pathogen in vitro. Arboric. Urban For. 34:317-324

McPherson, G. 2016. Potential Impact of PSHB and FD on Urban Trees in Southern California. Memorandum to J. N. Kabashima on April 26, 2016 United States Forest Service, Berkeley, CA. 
Mendel, Z., Protasov, A., Sharon, M., Zveibil, A., Yehuda, S. B., O’Donnell, K., Rabaglia, R., Wysoki, M., and Freeman, S. 2012. An Asian ambrosia beetle Euwallacea fornicatus and its novel symbiotic fungus Fusarium sp. pose a serious threat to the Israeli avocado industry. Phytoparasitica 40:235-238.

Mizell, R. F., and Riddle, T. C. 2004. Evaluation of insecticides to control the Asian ambrosia beetle, Xylosandrus crassiusculus. Pages 152-155 in: SNA Res. Conf., Vol. 49.

Na, F., Carrillo, J. D., Mayorquin, J. S., Ndinga-Muniania, C., Stajich, J. E., Stouthamer, R., Huang, Y. T., Lin, Y. T., Chen, C. Y., and Eskalen, A. 2018. Two novel fungal symbionts Fusarium kuroshium sp. nov. and Graphium kuroshium sp. nov. of Kuroshio shot hole borer (Euwallacea nr. fornicatus) cause Fusarium dieback on woody host species in California. Plant Dis. 102: 1154-1164.

Nishijima, W. T., and Smalley, E. B. 1978. Distribution and persistence of systemic fungicides in trunk injected elms. Pages 151-164 in: Proc. Symp. Syst. Chem. Treat. Tree Cult. J. J. Kielbaso, ed. Michigan State University, Ann Arbor.

Pajares, J. A., and Lanier, G. N. 1989. Pyrethroid Insecticides for Control of European Elm Bark Beetle (Coleoptera: Scolytidae). J. Econ. Entomol. 82: 873-878.

Peña, J. E., Crane, J. H., Capinera, J. L., Duncan, R. E., Kendra, P. E., Ploetz, R. C., McLean, S., Brar, G., Thomas, M. C., and Cave, R. D. 2011. Chemical control of the redbay ambrosia beetle, Xyleborus glabratus, and other Scolytinae (Coleoptera: Curculionidae). Fla. Entomol. 94:882-896.

Ploetz, R. C., Hughes, M. A., Kendra, P. E., Fraedrich, S. W., Carrillo, D., Stelinski, L. L., Hulcr, J., Mayfield, A. E., III, Dreaden, T. L., Crane, J. H., Evans, E. A., Schaffer, B. A., and Rollins, J. A. 2017. Recovery plan for laurel wilt of avocado, caused by Raffaelea lauricola. Plant Health Prog. 18:51-77.
Ploetz, R. C., Pérez-Martínez, J. M., Evans, E. A., and Inch, S. A. 2011. Toward fungicidal management of laurel wilt of avocado. Plant Dis. 95:977-982.

Rabaglia, R. J., Dole, S. A., and Cognato, A. I. 2006. Review of American Xyleborina (Coleoptera: Curculionidae: Scolytinae) occurring north of Mexico, with an illustrated key. Ann. Entomol. Soc. Am. 99:1034-1056.

Sarkar, D. 2008. Lattice: Multivariate Data Visualization with R. Springer Science \& Business Media, New York.

Stennes, M. A. 1981. Thiabendazole hypophosphite and carbendazim phosphate as systemic fungicides for practical Dutch elm disease control. M.S. thesis, University of Minnesota, St. Paul.

Stennes, M. A. 2000. Dutch elm disease chemotherapy with Arbotect 20-S and Alamo. Pages 173-188 in: The Elms: Breeding, Conservation, and Disease Management. C. E. Dunn, ed. Kluwer Academic Publishers, Boston.

Stennes, M. A., and French, D. W. 1987. Distribution and retention of thiabendazole hypophosphite and carbendazim phosphate injected into mature American elms. Phytopathology 77:707-712.

Stouthamer, R., Rugman-Jones, P., Thu, P.Q., Eskalen, A., Thibault, T., Hulcr, J., Wang, L.-J., Jordal, B. H., Chen, C.-Y., Cooperband, M., Lin, C.-S., Kamata, N., Lu, S.-S., Masuya, H., Mendel, Z., Rabaglia, R., Sanguansub, S., Shih, H.-H., Sittichaya, W., Zong, S. 2017. Tracing the origin of a cryptic invader: Phylogeography of the Euwallacea fornicatus (Coleoptera: Curculionidae: Scolytinae) species complex. Agric. For. Entomol. 19:366-375.

Svihra, P., Crosby, D. F., and Duckles, B. 2004. Emergence suppression of bark and ambrosia beetles in infested oaks. J. Arboric. 30:62-66.

USDA-APHIS. 2011. New Pest Response Guidelines: Exotic Wood-Boring and Bark Beetles. USDA-APHIS-PPQ-EDP-Emergency Management, Riverdale, MD. Venables, W. N., and Ripley, B. D. 2002. Modern Applied Statistics with S, Fourth ed. Springer Science+Business Media, New York. 